\title{
Overview of Innovative Mouse Models for Imaging Neuroinflammation
}

\author{
Céline Caravagna, ${ }^{1,2}$ Alexandre Jaouën, ${ }^{1,2}$ Franck Debarbieux, ${ }^{1,2,3}$ \\ and Geneviève Rougon ${ }^{1,2,3}$ \\ ${ }^{1}$ Aix Marseille Université, CNRS, Institut de Neurosciences de la Timone, Marseille, \\ France \\ ${ }^{2}$ Aix Marseille Université, Centre Européen de Recherche en Imagerie Médicale, Marseille, \\ France \\ ${ }^{3}$ These authors contributed equally to this work.
}

Neuroinflammation demands a comprehensive appraisal in situ to gain in-depth knowledge on the roles of particular cells and molecules and their potential roles in therapy. Because of the lack of appropriate tools, direct visualization of cells has been poorly investigated up to the present. In this context, reporter mice expressing cell-specific fluorescent proteins, combined with multiphoton microscopy, provide a window into cellular processes in living animals. In addition, the ability to collect multiple fluorescent colors from the same sample makes in vivo microscopy uniquely useful for characterizing many parameters from the same area, supporting powerful correlative analyses. Here, we present an overview of the advantages and limitations of this approach, with the purpose of providing insight into the neuroinflammation field. We also provide a review of existing fluorescent mouse models and describe how these models have been used in studies of neuroinflammation. Finally, the potential for developing advanced genetic tools and imaging resources is discussed. (C) 2016 by John Wiley \& Sons, Inc.

Keywords: adaptive immunity • intravital imaging • neuroinflammation • reporter mice

\section{How to cite this article:}

Caravagna, C., Jaouën, A., Debarbieux, F., and Rougon, G. 2016.

Overview of innovative mouse models for imaging neuroinflammation.

Curr. Protoc. Mouse Biol. 6:131-147.

doi: $10.1002 /$ cpmo.5

\section{INTRODUCTION}

In recent years, accumulating evidence has suggested that neuroinflammation is a major component of several central nervous system (CNS) pathologies. A prerequisite for a more comprehensive description of immunological processes in the brain is a thorough characterization of the function of the different immune cell types involved. This can only be achieved at the systemic level in animal models by long-term visualization and mapping of neuroimmune cellular dynamic interactions in the living brain. It is thus imperative to have reliable and reproducible tools and measures that are both sensitive and, more importantly, specific to neuroinflammation. The development and use of appropriate in vivo imaging methods can help in our understanding of the location and extent of neuroinflammation in different stages of a disorder, its natural time course, and its relation to neurodegeneration. Currently, there is only a small amount of in vivo evidence derived from neuroimaging methods because the methods and models that are actually specific and sensitive to neuroinflammation are relatively new or only just being developed.

Moreover, given the CNS complexity and diversity of pathologies involving neuroinflammation, neither a single animal model nor a single imaging modality will ever yield precise information on all aspects of neuroinflammation. Therefore, while several animal models have already been used to study neuroinflammation, more are needed. Because of the powerful genetic tools available, the mouse
Mouse Models for Imaging Neuroinflammation 
has proven to be a highly useful mammalian system for studying the pathophysiology of human diseases.

The main purpose of this review is not to present an exhaustive summary of recent studies but rather to illustrate the unique application of fluorescently labeled mice for detailed long-term monitoring of motile immune cells in the healthy CNS as well as in a context of disease. To do so, we will make a case for the multiphoton imaging approach as a discovery platform in the field of neuroimmunology and brain disease research to help decipher in vivo mechanisms that cannot otherwise be studied. Data derived from these studies help to generate hypotheses, provide unexpected novel in vivo insights, and sometimes allow for rapid preclinical development.

\section{CELLS IMPLICATED IN NEUROINFLAMMATION}

Neuroinflammation is observed in many brain disorders, especially those with a neurodegenerative course such as stroke, multiple sclerosis (MS), Alzheimer's disease, and Parkinson's disease (Weiner and Selkoe, 2002; Schwartz, 2003), but also in schizophrenia and malignant CNS neoplasms (e.g., glioblastoma multiforme; Kore and Abraham, 2014), among many others. Depending on the specific condition, different cell types and molecular mediators (e.g., cytokines, chemokines; Kore and Abraham, 2014) participate in a cascade of events that leads to damage of brain tissue but ultimately also controls brain repair.

The brain parenchyma is separated from peripheral tissue by the blood brain barrier (BBB), which prevents blood immune cells from entering the brain under normal conditions (Zlokovic, 2008; McAllister and van de Water, 2009). Indeed, the CNS has its own innate immune system that operates mainly through the activation of astrocytes and microglial cells as part of neuroinflammation (Schwartz, 2003).

Microglial cells are the resident macrophages of the brain (Ginhoux et al., 2010; Kierdorf et al., 2013; Perdiguero et al., 2014). In contrast to other populations of myeloid lineage, adult microglial cells derive from primitive myeloid precursors that arise in the yolk sac early during embryonic development (Ginhoux et al., 2010). Postnatally, microglia have the potential for cell renewal without contribution of blood-born myeloid precursors. Upon signals induced by injury, microglial cells have been shown to adapt their phenotypes and functions to protect neurons and to signal the peripheral immune system through the release of chemical signals (London et al., 2013).

Microglial cells are usually the initial responders to tissue insult or damage. They are activated in response to molecules present in injured tissue. When active, the cells change their shape and function to initiate phagocytosis. In addition, activated microglial cells, in concert with astrocytes, release cytokines (Aloisi et al., 2000) that lead to a cascade of events modulating the neuroinflammatory response. As part of this process, the glial cells also release cytotoxic metabolites (Banati et al., 1993) that can damage surrounding tissue. Microglial cell activation and proliferation occurs in almost any single pathology affecting the CNS and, depending on the level of activation, may lead to the infiltration of deleterious peripheral leucocytes. Therefore, activation was seen more as a problem than an advantage, and the use of drugs has been proposed to prevent microglial cells activation (Aisen, 2002; Gao et al., 2003; Block and Hong, 2005; Rock and Peterson, 2006). However, similarities between macrophages and microglial cells led to the suspicion that the latter might also differentiate into a state that is beneficial instead of harmful for neurons (London et al., 2013).

Although astrocytes are of ectodermal origin, they have immunological capabilities as well (Gimsa et al., 2013). When activated, astrocytes are supposed to produce immunoregulatory cytokines (e.g., TGF- $\beta$; Hailer et al., 1998; Aloisi et al., 2000), but an additional role as antigen presenting cells (APCs) has also been proposed (Aloisi et al., 2000). In MS lesions, reactive astrocytes express CD1 molecules, particularly CD1b (Battistini et al., 1996), which can present lipid antigens to specialized T-cell subsets (Naidenko et al., 2000) suggesting that astrocytes could participate in the presentation of non-peptide antigens to $\mathrm{T}$ cells. However, unlike microglial cells, astrocytes do not express CD11 (Yang et al., 2010). Moreover, in vivo, while microglial cells express MHC-II readily upon activation, astrocytic MHC-II expression occurs only at high cytokine doses (Hindinger et al., 2012). A recent review describes the known roles of astrocytes in neuroinflammation (Gimsa et al., 2013), although much remains to be deciphered.

Whereas circulating monocytes invade the CNS parenchyma under neuroinflammatory conditions, it appears that they are 
highly versatile and heterogeneous. The mononuclear phagocyte system, defined as a hematopoietic cell lineage derived from progenitor cells in the bone marrow, is composed of three major cell types: monocytes, macrophages, and dendritic cells (DCs). Furthermore, two types of monocytes exist, including classical $\left(\mathrm{Ly} 6 \mathrm{C}^{\mathrm{hi}} \mathrm{CCR} 2^{+} \mathrm{CX} 3 \mathrm{CR} 1^{\text {lo }}\right.$ ) and non-classical (Ly6C ${ }^{\mathrm{lo}} \mathrm{CCR} 2^{-} \mathrm{CX} 3 \mathrm{CR} 1^{\mathrm{hi}}$ ) monocytes (see below for markers). Both types cross the BBB under pathological conditions. The former are pro-inflammatory and infiltrate the CNS in a chemokine-dependent manner through leptomeningeal routes; the latter are involved in the resolution of inflammation but have to transmigrate through the ventricular choroid plexus epithelium before arriving at the site of inflammation (Shechter et al., 2013). The molecular and functional phenotype of these monocytes evolves according to the signals that they encounter in the brain parenchyma.

Current evidence concerning microglial cells suggests that macrophages in the CNS can not only contribute to the generation of inflammatory lesions but also block inflammation, thus participating in regenerative and repair mechanisms (Shechter et al., 2013). These studies emphasize that distinct functions are attributed to the different subsets of myeloid cells in the course of CNS inflammation. However, it is difficult to delineate resident microglial cells from infiltrating myeloid cells using currently known markers (e.g., CD45/CD11b, CX3CR1, Iba1). As such, a complete understanding of microglial and monocyte-derived cell types based on surface phenotype combined with imaging techniques documenting their parenchymal localization, differentiation kinetics, and interactions would be of great benefit in preclinical models of CNS inflammation.

\section{MARKERS EXPRESSED BY MICROGLIAL CELLS VERSUS MYELOID CELLS}

A very comprehensive review of what is presently known concerning markers for microglial- and monocyte-derived cells has been recently published (Greter et al., 2015). Data are summarized in Table 1.

CD11c is a widely used marker of DCs and microglial cells. CD11c is a leukocyte integrin comprising an alpha $\mathrm{X}$ subunit that, along with CD18 (a leukocyte beta 2 integrin polypeptide), forms the $\mathrm{CD} 11 \mathrm{c} / \mathrm{CD} 18$ heterodimer. This heterodimer is important in leukocyte adhesion, migration, and cell-tocell interaction during immune responses. Beside its primary expression in APCs of the meninges and choroid plexus in resting conditions (Anandasabapathy et al., 2011), CD11c is also expressed at lower levels on other infiltrated immune cells such as natural killer (NK) cells, subpopulations of macrophages, and activated T cells (Lindquist et al., 2004). Whereas CD11c has been widely targeted to identify microglial cells in transgenic mice as described below, the specific identification of microglial cells in injured CNS is quite challenging.

Presently, a consensus with respect to nomenclature in CNS-resident versus CNSinfiltrating myeloid cells under inflammatory conditions has not been effectively reached. A more detailed separation of these cell types in an inflamed brain is needed to help decipher the specialized functions of their different members in pathological conditions. This will

Table 1 Central Nervous System (CNS) Myeloid Cells and Their Defining Lineage Markers ${ }^{a}$

\begin{tabular}{|c|c|c|}
\hline State & Cell & Markers \\
\hline \multirow[t]{3}{*}{ Steady state } & Microglia (resting) & $\begin{array}{l}\mathrm{CD} 45^{\text {low }} ; \mathrm{CX}_{3} \mathrm{Cr}^{\text {high }} ; \mathrm{F} 4 / 80^{+} ; \mathrm{CD} 11 b^{+} ; \mathrm{CD} 115^{+} ; \\
\mathrm{MerTK}^{+} ; \mathrm{CD}^{+} 4^{+} ; \text {Siglec-H }^{+} ; \mathrm{FCRLS}^{+} ; \mathrm{P} 2 \mathrm{ry} 12^{+}\end{array}$ \\
\hline & Perivascular macrophage & $\mathrm{CD}_{4} 5^{\text {high }} ; \mathrm{CX}_{3} \mathrm{Cr} 1^{\text {high }} ; \mathrm{F} 4 / 80^{+} ; \mathrm{CD}_{11 b^{+}} ; \mathrm{CD} 115^{+}$ \\
\hline & Monocyte (in the blood) & $\begin{array}{l}\mathrm{CD} 45^{\text {high }} ; \mathrm{CX}_{3} \mathrm{Cr} 1^{\text {low }} ; \mathrm{F} 4 / 80^{+} ; \mathrm{CD} 11 \mathrm{~b}^{+} ; \mathrm{CD} 115^{+} ; \\
\mathrm{Ly} 6 \mathrm{C}^{\text {high }} ; \mathrm{CCR}^{+}\end{array}$ \\
\hline \multirow[t]{2}{*}{ Inflammation } & $\begin{array}{l}\text { Macrophage (in the brain } \\
\text { parenchyma) }\end{array}$ & $\begin{array}{l}\mathrm{CD} 45^{\text {high }} ; \mathrm{CX}_{3} \mathrm{Cr}^{\text {low }} ; \mathrm{F} 4 / 80^{+} ; \mathrm{CD}_{11 b^{+}} ; \mathrm{CD}_{115^{+}} ; \\
\mathrm{CD}^{+} 4^{+} ; \mathrm{Ly} 6 \mathrm{C}^{ \pm} ; \mathrm{CCR}^{ \pm} ; \mathrm{MHCII}^{+} ; \mathrm{CD} 11 \mathrm{c}^{\text {int }}\end{array}$ \\
\hline & Microglia (activated) & $\begin{array}{l}\mathrm{CD} 45^{\text {high }} ; \mathrm{CX}_{3} \mathrm{Cr} 1^{\text {high }} ; \mathrm{F} 4 / 80^{+} ; \mathrm{CD}_{11 b^{+}} ; \mathrm{CD} 115^{+} \text {; } \\
\mathrm{MHCII}^{\text {int }} ; \mathrm{CD}_{11} \mathrm{c}^{\text {int }}\end{array}$ \\
\hline
\end{tabular}

${ }^{a}$ In the steady state and under inflammatory conditions, myeloid cells in the CNS express a diverse, yet overlapping set of markers commonly used to discriminate between mononuclear phagocyte system members. Adapted from (Greter et al., 2015).

Mouse Models for Imaging Neuroinflammation 
be assisted by the advent of microarray technology and next generation sequencing (Das et al., 2015).

\section{IMAGING NEUROINFLAMMATION}

In vivo imaging data can assist in achieving an understanding of the dynamics of mechanisms involved in inflammation at the cellular level. However, many neuroinflammation imaging techniques, such as magnetic resonance imaging (MRI; Pasternak et al., 2015), do not display sufficient sensitivity to perform studies at a cellular level.

\section{PET/SPECT}

The methods that are specific and sensitive to neuroinflammation are relatively new or only just being developed. Positron emission tomography (PET) is currently one of the main neuroimaging modalities used to identify neuroinflammation in vivo (Jacobs and Tavitian, 2012). Single-photon emission computed tomography (SPECT) is based on similar principles as PET, with technical modifications making SPECT less sensitive when tracer concentrations are low but more accurate spatially. The PET scanner produces three-dimensional (3D) images representing the counts of detected gamma rays emitted by tracers, which are radionuclides chemically incorporated into a biologically compatible or biologically active molecule. In the case of inflammation, the main tracer used is 1-(2-chlorophenyl)-N-methylN-(1-methyl-propyl)-3-isoquinoline carboxamide (PK11195), which is a ligand for a protein of the outer mitochondrial membranethe translocator protein-18-kd (TSPO; Venneti et al., 2013)—expressed during mitochondrial activation (Saba et al., 2015). The technique allows the study of temporal dynamics of this molecular neuroinflammatory component in vivo in animal models. Quantification of TSPO in mice is, however, quite challenging (Tóth et al., 2015). TSPO is located exclusively in glial cells in the brain parenchyma (Chen and Guilarte, 2008) and confined to areas such as the choroid plexus, the ependymal layer, and in perivascular cells in the normal healthy brain (Kannan et al., 2009). In the injured nervous system, increased TSPO levels are specific to primary or secondary areas of injury expressing activated microglial cells (Chen and Guilarte, 2008). TSPO is also expressed, albeit to a lesser extent, in reactive astrocytes (Rupprecht et al., 2010). This is a limitation for the use of this molecule, since the different cell types expressing it have different roles in the resolution of neuroinflammation. Moreover, although state-of-the-art small-animal devices are being constructed with resolutions of $0.8 \mathrm{~mm}$ or better that approach the physical limits for emission of carbon-11 or fluorine18 , the imaging technique lacks the resolution that would otherwise allow the differentiation of the various cell types. Finally, a disadvantage of PET utilization is also that radioactive animals must be housed in a manner that satisfies radioactivity safety requirements.

\section{Multiphoton Excitation Fluorescence Microscopy}

In contrast, recent developments in fluorescence imaging technology, together with the generation of transgenic mice expressing fluorescent proteins linked to specific endogenous proteins, make the mouse a powerful model organism to study neuroinflammation. In particular, two-photon (2P) excitation fluorescence microscopy allows subcellular-scale 3D imaging of complex media over depths of several hundred micrometers, and it has become an indispensable tool for volume and live-tissue studies. It is highly sensitive and has good specificity, which makes it useful for imaging the physiology, morphology, and cell-cell interactions in inflamed tissue of living animals with high resolution and for viewing cellular events in real time. Due to the excitation wavelength (700 to $1200 \mathrm{~nm}$ in the nearinfrared range) tissue scattering and absorption are minimized, allowing maximization of imaging penetration depth (Niesner et al., 2008; Hoover and Squier, 2013). Moreover, nanomolar concentrations of fluorophores can be detected in vivo in volumes as small as few $\mu \mathrm{m}^{3}$ (Malcor et al., 2012), comparable to PET scan sensitivity of femtomolar concentrations in $\mathrm{mm}^{3}$.

In addition, when illuminated by the short duration, high-intensity laser pulses (1 watt) required for $2 \mathrm{P}$ microscopy, ordered structures such as collagen (Fig. 1), tubulin, and myosin are responsible for the recombination of two low-energy photons into a single photon of double- or triple-energy during a process known as second or third harmonic generation (Tsai et al., 2012). Emission of second harmonic photons thus provides an endogenous contrast that allows for morphological observation in collagen-rich or microtubulerich structures such as the lymph node and the brain (Kwan et al., 2009; Winkler et al., 2010; Güç et al., 2014). 


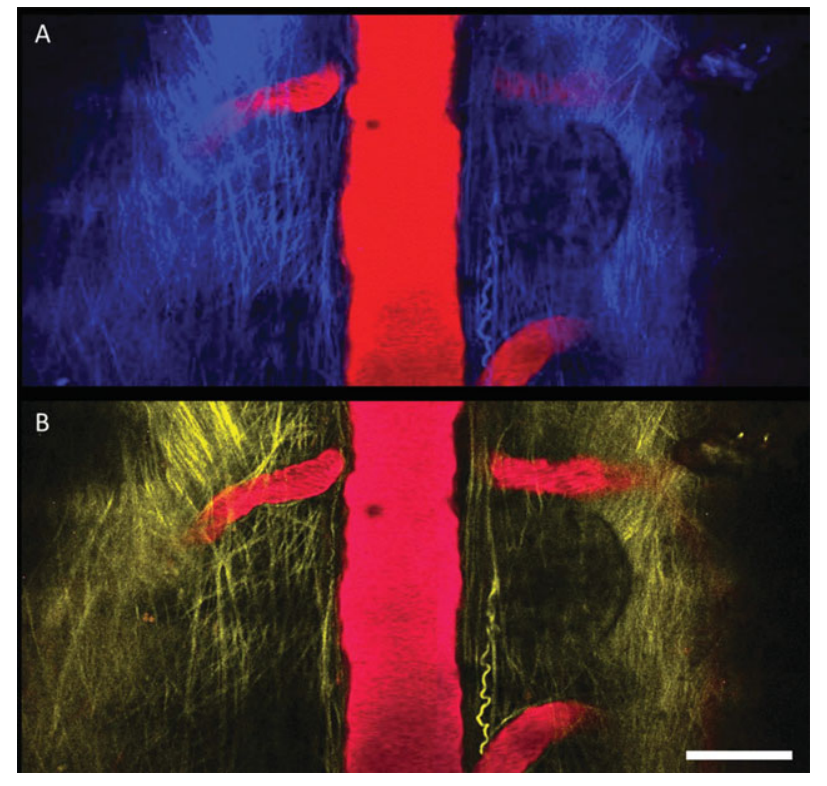

Figure 1 Endogenous contrast revealed by intravital microscopy provides information on the micro-organization of collagen in the superficial layers of the spinal cord of a healthy wild-type adult mouse. (A) When excited at $1050 \mathrm{~nm}$, endogenous second harmonic signal (blue) and blood vessel fluorescent signal (red) following injection of 655-Qdot probes are visible. (B) When excited at $940 \mathrm{~nm}$, endogenous second harmonic signal (yellow) and blood vessel fluorescent signal (pink) following injection of 655-Qdot probes are visible. Scale bar: $20 \mu \mathrm{m}$.

However, until recently, implemented methodology did not provide simultaneous, efficient, and independent multiphoton excitation of more than two spectrally distinct chromophores, but recent significant improvements in this direction have been achieved (Mahou et al., 2012; Ricard and Debarbieux, 2014).

Imaging inflammation in the CNS requires chronic imaging of the same area for long periods of time (i.e., days). A variety of techniques have been used to access the cortex, with the thinned skull and cranial window techniques dominating in the literature. The thinned skull technique (Marker et al., 2010) consists of drilling the skull enough to allow 2P imaging of the underlying brain. The advantage of this method is the reduced risks of tissue injury, but the inconvenience is the inhomogeneity of the overlying bone layer, hence inhomogeneous optical properties and limited depth. The cranial window technique consists of the full removal of part of the skull and its replacement by a thin glass window, thus improving sensitivity and imaging depth.

Careful consideration of both sterile technique and surgical expertise are paramount to a successful imaging experiment regardless of the approach taken, since both techniques can lead to transient inflammation. A very com- prehensive review comparing and contrasting the pros and cons of each method has been recently published (Dorand et al., 2014). Similarly, a few techniques have been developed for implanting and maintaining windows over the spinal cord of adult mice for high-throughput imaging data acquisition (Fenrich et al., 2012; Tang et al., 2014). Such glass windows are not required when using the eye as a model. Having accounted for the optical properties of the eye, the corneal model of inflammation offers unique advantages for direct in vivo visualization of infiltrating and resident immune cells with minimal surgical manipulation (Chen et al., 2013). However, since the eye is not part of the CNS, extrapolation of the results to CNS diseases is limited.

\section{Limitations of Multiphoton Microscopy}

Although $2 \mathrm{P}$ microscopy is clearly a very promising technology, it poses some challenges. First of all, it requires the presence of fluorescence in the sample. This has to be introduced into living animals, as discussed in the following section. Then, because each image is acquired pixel by pixel, the volume of tissue that can be imaged in a reasonable time (typically $1 \mathrm{hr}$ ) is small (i.e., a few $\mathrm{mm}^{3}$ ). Therefore, the density of fluorescent objects
Mouse Models for Imaging Neuroinflammation 
of interest within the imaged tissue must be high enough to ensure that they will be present there. Nevertheless, parsimonious density of fluorescent objects is preferable to uniform distribution in the whole tissue since the contrast is optimal for objects surrounded by dark space or by different colors. Another limitation is the presence of physiological respiratory and heart movements that impede the desired micrometric resolution of cell processes. These movements can, however, be partially compensated by image acquisition gating (Taylor et al., 2011), on line autofocussing (Laffray et al., 2011), or postacquisition registration (Rohde et al., 2005). Solutions to these problems are awaiting the development of fast, noninvasive whole body imaging methods with single cell resolution.

\section{Exogenous Fluorescent Labels}

Exogenous fluorescent labels can be used to label vascularization or cells of interest ex vivo prior to reinjection in the subject (Table 2). For example, blood vessels can be highlighted by injection of a fluorescent marker such as $70 \mathrm{kDa}$ dextran, conjugated to either fluorescein or rhodamine B isothiocyanate. The interest of fluorescent dextrans is that they can be taken up by macrophages from the vascular compartment within a few hours, resulting in a long-term intravital labeling of macrophage populations (Fig. 2). For selective labeling of the vascular compartment, quantum dots are preferred to labeled dextran as they barely accumulated in phagocytic cells (Fig. 1; Fenrich et al., 2012). Quantum dots are small, inorganic nanoparticles that emit a specific wavelength of light depending on their size, from ultraviolet to near infrared. Moreover, these nanoparticles are promising scaffolds for other imaging applications (e.g., designing quantum-dot surfaces with various functionalities for use as nanosensors or as fluorescent probes; Utschig et al., 2015).

We have emphasized the diversity of cells involved in neuroinflammation and the set of markers allowing their phenotyping as well as outlined the importance of studying their kinetics of recruitment, distribution, and interactions. Some of the earliest studies to visualize the immune response in situ were performed using adoptive transfer of exogenously labeled cells. In this context, cell populations collected in vivo were purified and labeled with fluorescent dyes (usually with nonoverlapping emission spectra), such as CFSE (Koyanagi et al., 2015), SNARF (Singh et al., 2011), CMAC (Tauskela et al., 2000) or DiI (Vandepitte et al.,
2010). Although this has been useful for shortterm trafficking and migration studies, cell division results in the dilution of dyes and makes them difficult to track.

\section{Cell-Type-Specific Expression of Fluorophores Requires Genetic Systems}

Genetically encoded proteins represent fantastic new tools for long-term labeling, manipulation, and characterization of inflammatory cells in real time and with cellular specificity. Since the breakthrough discovery of the green fluorescent protein (GFP; Prendergast and Mann, 1978), a protein that can be excited with blue light to emit green fluorescence, a large number of other fluorescent proteins have been discovered and constantly optimized. Today, they comprise a palette of proteins spanning the spectrum from ultraviolet to far red, laying the basis for multicolor imaging (Stepanenko et al., 2011). Usually, they exhibit very high extinction coefficients and very high quantum yields, properties making them very bright. Genes coding for fluorescent proteins can be introduced into the mouse genome to be expressed in specific cells thanks to specific promoters. This addition provides a unique and selective way to label subpopulations of cells that can be visualized under conventional or 2P microscopy. Moreover, fluorescent molecules can be linked to multiple proteins with various functions, such as calcium (Jiang et al., 2014), voltage (Gong, 2015), glutamate (Marvin et al., 2013), or caspase (Yan et al., 2014) sensors. These conjugated molecules allow for the activation of the fluorescent protein when the sensor binds to the appropriate stimulus molecule. The fluorescent proteins can be cytoplasmic, nuclear, or membranous. Care should be taken so that the localization of the large fluorescent protein does not impede cell physiology or receptor signaling. Years of experience seem to indicate that cytoplasmic expression is usually safe for the cells. These activity probes are powerful tools to visualize specific responses of the targeted cells. They can be combined with previously described genetically encoded fluorescent proteins to identify the cell type.

\section{FLUORESCENT MICE ALLOWING CELL VISUALIZATION TO DECIPHER THE DYNAMICS OF INFLAMMATORY RESPONSES}

The generation of various reporter mice expressing fluorescent proteins under promoters specific for different cell types (e.g., 
Table 2 Wavelengths of Excitation and Emission of Commonly Used Dyes ${ }^{a}$

\begin{tabular}{|c|c|c|c|c|}
\hline Visualization molecules & Abbreviation & $\begin{array}{l}\text { Bi-photon } \\
\text { excitation }\end{array}$ & $\begin{array}{l}\text { Conventional } \\
\text { excitation }\end{array}$ & Emission \\
\hline \multirow{4}{*}{$\begin{array}{l}\text { Fluorescent proteins, } \\
\text { jellyfish-derived }\end{array}$} & eBFP & 780 & 380 & 440 \\
\hline & eCFP & $860-920$ & 433 & 475 \\
\hline & eGFP & $880-930$ & 488 & 509 \\
\hline & eYFP & 960 & 513 & 527 \\
\hline \multirow{5}{*}{$\begin{array}{l}\text { Fluorescent proteins, } \\
\text { coral-derived }\end{array}$} & Kaede (before conversion) & 730 & 508 & 518 \\
\hline & Kaede (after conversion) & 730 & 572 & 582 \\
\hline & tdTomato & $900-1000$ & 554 & 581 \\
\hline & DsRed & $930-990$ & 558 & 583 \\
\hline & mCherry & $\begin{array}{c}760 \text { or } \\
900-1000\end{array}$ & 587 & 610 \\
\hline \multirow[t]{8}{*}{ Chemical dyes } & $\mathrm{CMF} 2 \mathrm{HC}$ & $780-800$ & 371 & 464 \\
\hline & CFSE & $780-820$ & 492 & 517 \\
\hline & CMFDA & 800 & 492 & 517 \\
\hline & FITC & $780-800$ & 494 & 520 \\
\hline & CMTMR & $780-820$ & 541 & 565 \\
\hline & SNARF & $700-810$ & 563 & 639 \\
\hline & CMTPX & $780-800$ & 577 & 602 \\
\hline & Texas Red & $780-920$ & 595 & 615 \\
\hline \multirow[t]{8}{*}{ Calcium indicators } & Indo-1 & 700 & 346 & 475 \\
\hline & Indo-1 with $\mathrm{Ca}^{2+}$ & 700 & 330 & 401 \\
\hline & Fura-2 & $700-850$ & 363 & 512 \\
\hline & Fura-2 with $\mathrm{Ca}^{2+}$ & $700-850$ & 335 & 505 \\
\hline & Fura-4 F & $700-850$ & 366 & 511 \\
\hline & Fura-4 F with $\mathrm{Ca}^{2+}$ & $700-850$ & 336 & 505 \\
\hline & TN-XXL & 800 & 433 & 475 \\
\hline & TN-XXL with $\mathrm{Ca}^{2+}$ & 800 & 433 & 527 \\
\hline \multirow[t]{7}{*}{ Organelle visualization dyes } & Hoechst & 780 & 350 & 461 \\
\hline & DAPI & 700 & 358 & 461 \\
\hline & FM 1-43 & 830 & 480 & 565 \\
\hline & Rhodamine 123 & $780-860$ & 507 & 529 \\
\hline & DiI & 700 & 549 & 565 \\
\hline & Sulforhodamine 101 & $840-890$ & 586 & 605 \\
\hline & DiD & 780 & 644 & 665 \\
\hline
\end{tabular}

${ }^{a}$ Adapted from Kawakami and Flügel (2010).

DCs, neutrophils, macrophages) has permitted long-term tracking of many different types of immune cells in vivo. Moreover, the most important consequence of neuroinflammation being damage to axons/neurons, it is particularly interesting to generate mice allowing direct observation of axonal damages.
In this section we have compiled the existing and most used transgenic reporter mouse lines. Most of them are available through The Jackson Laboratory (JAX Repository). There are no indications in the published data that the fluorescent proteins are toxic to the animals. We have highlighted in a
Mouse Models for Imaging Neuroinflammation 

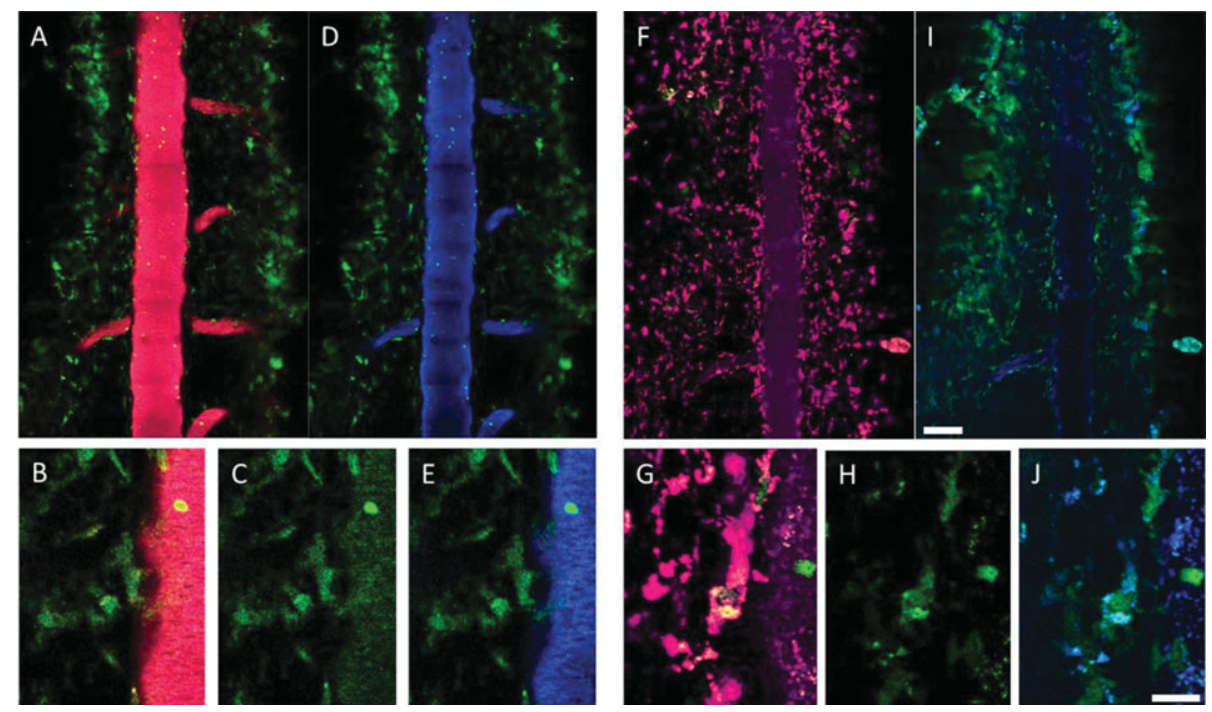

Figure 2 Intravital labeling for two-photon microscopic imaging of phagocytic immune cell populations in adult mouse spinal cord. (A-E) Spinal cord of a LysM-eGFP+ mouse immediately after injection of Texas Red $70 \mathrm{kDa}$ dextran (A and B) or Cascade Blue $70 \mathrm{kDa}$ dextran (D and E). LysM-eGFP cells (green, $C$ ) are present in both the blood and the parenchyma. Note that the dye is confined to the blood vessels where LysM-eGFP+ cells (green) circulate. (F-J) After injection (72 hr) of Texas Red ( $F$ and $G$ ) or Cascade Blue ( $I$ and $J)$ dextran, the dye is mainly accumulated in LysM-eGFP cells (green, $\mathrm{H}$ ) of the brain parenchyma and faintly labels the blood vessels. Scale bar A, D, F, I: $100 \mu \mathrm{m}$; B, C, E, G, H, J: $20 \mu \mathrm{m}$.

few examples of how, when combined with optimized imaging conditions, these models have led to basic insight in disease related processes.

\section{Microglial Cells, DCs: CD11c-Related Lines}

The CD11c-eYFP, also known as the B6.Cg- $\mathrm{Tg}$ (Itgax-Venus) $1 \mathrm{Mnz} / \mathrm{J}$ line (Lindquist et al., 2004), and CD11c-DTR/GFP (Jung et al., 2002) transgenic reporter mice were created to overcome the difficulty of distinguishing subpopulations of macrophages from cells of DC lineage. In these transgenic mice, the mouse integrin alpha X (Itgax, Cd11c) gene promoter, which is exclusively expressed in DCs of the immune system and in a subpopulation of microglial cells, is used to drive a fluorescent protein (CD11c-eYFP mice) and the diphtheria toxin (DT) receptor expression (CD11c-DTR/GFP mice). Mice are not sensitive to DT, as they lack a receptor. Consequently, a selectively expressed human DT receptor can be used to eliminate the targeted population. The co-expressed fluorescent marker may be used to measure the extent to which the target population is depleted, as well as the kinetics of its repopulation (Cailhier et al., 2005). A conditional mutation (CD11c-Cre-GFP mouse line) is also available through The Jackson Laboratory. Such mice have been used to assess distribution and mobility of DCs in the periphery and to anatomically map and phenotype a discrete population of eYFP-positive cells within the microglial cells (Bulloch et al., 2008).

In the C57BL/6J-Tg(Itgax-cre,-EGFP) 4097Ach/J and NOD.B6-Tg(Itgax-cre,EGFP)4097Ach/J lines, the CD11c promoter directs bicistronic Cre and eGFP protein expression to DCs resulting in equimolar expression of eGFP and Cre recombinase. When bred with mice containing a loxP-flanked sequence of interest, the resulting offspring may have a Cre-mediated recombination of the flanked sequence thus allowing the selective identification of DC and microglial cell populations.

In MHC-eGFP mice (Boes et al., 2002), the endogenous class II product is replaced by a fluorescently tagged version, encoding a protein composed of an intact class II chain fused at its carboxyl terminus with eGFP. The MHC II-eGFP mice are phenotypically normal.

\section{Microglial Cells, Macrophages: CX3CR1-Related Lines}

Similar reporter mice were generated by targeting fractalkin receptor CX3CR1 whose 

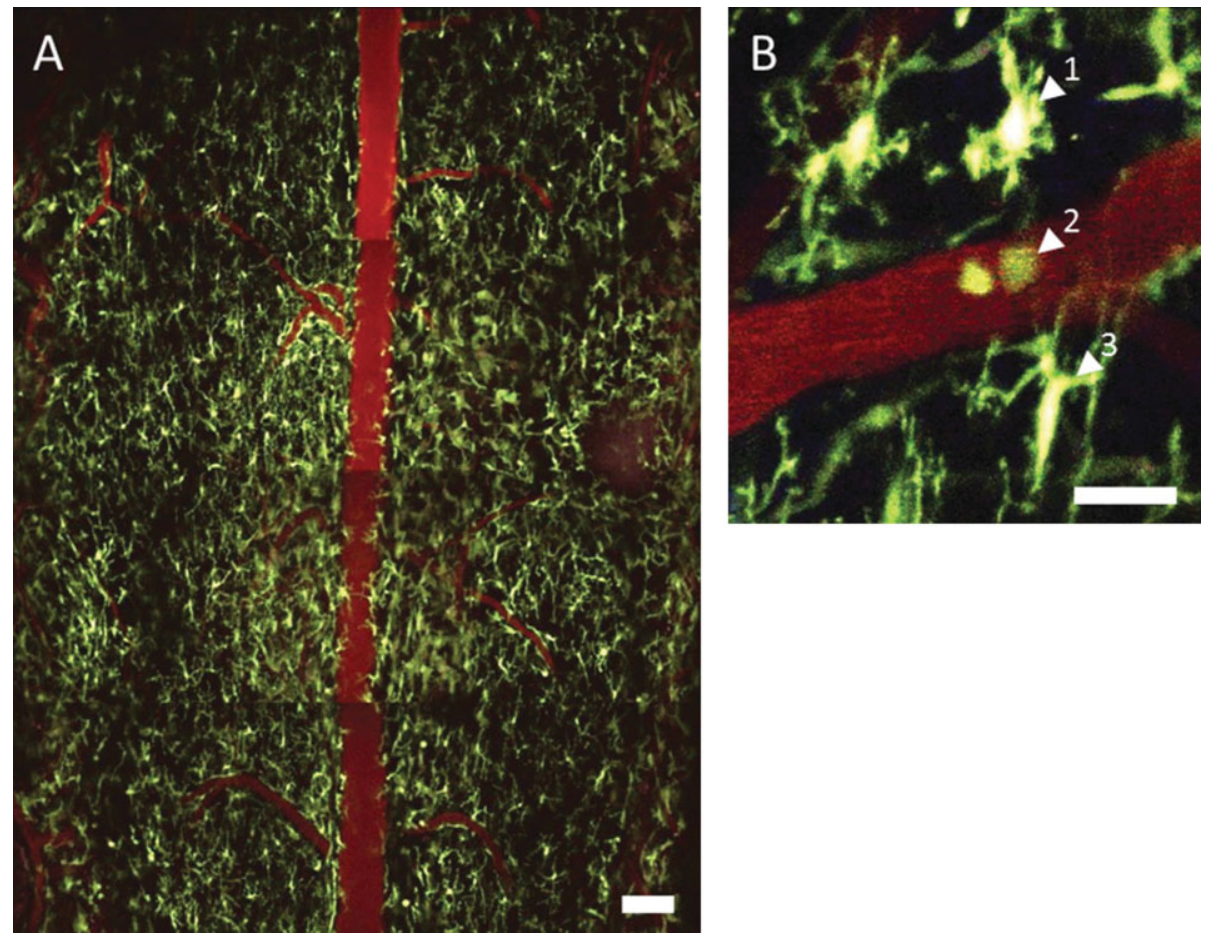

Figure 3 Green fluorescent resident microglial cells and circulating monocytes in CX3CR1eGFP mouse. (A) Two-photon microscopy images of the inflamed spinal cord in a CX3CR1-eGFP mouse following injection of $655-Q d o t s$ probes after experimental autoimmune encephalomyelitis (EAE) induction. Spinal cord central vein (red) is surrounded by high densities of CX3CR1expressing microglial cells (green). Scale bar: $100 \mu \mathrm{m}$. (B) Labeled cell populations include microglial cells at different stages of differentiation (white arrows 1 and 3) as well as circulating monocytes/macrophages (white arrow 2). Scale bar: $30 \mu \mathrm{m}$.

expression is high in microglial cells and mature macrophages (Fig. 3).

In $\mathrm{CX} 3 \mathrm{CR} 1^{\mathrm{GFP} /+}$ knock-in (KI) mice, one copy of the CX3CR1 gene has been replaced by GFP, leaving the endogenous promoter intact (Jung et al., 2000). In heterozygous animals, CX3CR1 expression remains detectable because the animals possess one allele for fluorescence visualization of cells expressing CX3CR1 and one allele for expression of the functional receptor.

B6.129P(Cg)-Ptprc ${ }^{\mathrm{a}}-\mathrm{CX} 3 \mathrm{CR} 1^{\mathrm{tm} 1 \mathrm{Litt}} / \mathrm{LittJ}$ and B6.129P-CX3CR $1^{\text {tm1Litt } / J}$ are two different lines of mice where eGFP, but not the endogenous gene, is expressed in brain microglial cells as well as monocytes, DCs, and NK cells (Jung et al., 2000). Peripheral blood from heterozygous mice expresses detectable levels of eGFP in the same cell subsets. Heterozygous mice are viable, fertile, normal in size, and do not display any gross physical or behavioral abnormalities. This makes them suitable for studies of immune cell migration or trafficking, without distinguishing cell subsets and without functional studies.
To gain insight into the functional impact of these cells and avoid any developmental issue, another strain was designed for induced CX3CR1 deletion at determined ages. B6.129P2(Cg)-CX3CR $1^{\text {tm } 2.1(\mathrm{cre} / \mathrm{ERT}) \mathrm{Litt} /}$ WganJ are CX3CR1 ${ }^{\text {CreER }}$ mice expressing a Cre-ER fusion protein and eYFP from endogenous CX3CR1 promoter/enhancer elements (Littman, 2013; Parkhurst et al., 2013). eYFP immunofluorescence is observed in CX3CR1expressing microglial cells, mimicking endogenous gene expression patterns. When CX3CR $1^{\text {CreER }}$ mice are bred with mice containing loxP-flanked sequences, tamoxifeninducible, Cre-mediated recombination will result in deletion of the floxed sequences. When bred with mice containing a loxPflanked STOP cassette upstream of a red fluorescent protein (DsRed) sequence, $93.9 \%$ of CX3CR1-eYFP ${ }^{+}$microglial cells were found to coexpress YFP and DsRed after 5 days of tamoxifen treatment. Only a few DsRed ${ }^{+}$ microglial cells $(0.3 \% \pm 0.01 \%)$ were found in the brain in the absence of tamoxifen (Parkhurst et al., 2013).
Mouse Models for Imaging Neuroinflammation 
Monocytes and Macrophages: CD68, LysM, and CD11B

Three main mouse lines have been generated to preferentially highlight myeloid cells and monocytic populations. In the C57BL/6$\mathrm{Tg}(\mathrm{CD} 68$-EGFP)1Drg/J line (Iqbal et al., 2014), hCD68-GFP transgenic mice express eGFP under the control of human CD68 promoter/enhancer sequences. Whereas eGFP is observed in tissue-resident macrophages including microglial cells, it is expressed in $100 \%$ of bone marrow monocytes and $60 \%$ of bone marrow-derived neutrophils (Iqbal et al., 2014). Adoptively transferred CD68GFP monocytes that traffic to the sites of inflammation retain high-level GFP expression $72 \mathrm{hr}$ after differentiation into macrophages in situ (Iqbal et al., 2014).

The C57B1/6J-LysM-eGFP mouse line (Faust et al., 2000) has been generated by homologous recombination in order to insert the eGFP gene into the LysM locus. This method was chosen because LysM is specifically expressed in the myelomonocytic cell lineage (macrophages and neutrophil granulocytes; Faust et al., 2000). In adult healthy mice, LysM-eGFP cells are only found in the blood. Their characterization revealed that the eGFP high polymorphonuclear (PMN) granulocytes outnumbered LysM-eGFP monocytes by five to one (Faust et al., 2000). Homozygous animals are viable but exhibit an increased inflammatory response due to the complete deletion of lysozyme 2 gene. Although conditional mutant mice for LysM do exist in The Jackson Laboratory Repository, their transgenic construct does not include any reporter gene. These mice should then be crossed with classical LysM-eGFP mice to combine visualization and inducible deletion.

The B6.FVB-Tg(ITGAM-DTR/EGFP)34Lan/J mice theoretically express weak eGFP in monocytes/macrophages under the control of the human CD11b promoter along with a DT inducible system (Duffield et al., 2005). Although intraperitoneal injection of DT ablates monocyte/macrophage cells in the peritoneal cavity, in the kidney and ovary it fails to influence hepatic sinusoidal and alveolar macrophages, as well as recruited or circulating PMNs, despite PMN leukocyte expression of CD11b (Duffield et al., 2005). However, transgene expression is not sufficient to be detected by fluorescence-activated cell sorting (FACS) analysis in these mice, and in all cases the macrophage population is restored by day 4 following a single intraperitoneal dose of DT (Duffield et al., 2005).
Recently, several fluorescent reporters have been developed for cytokines, including IL2 , IL-10, IL-12, and IFN- $\gamma$, making it possible to visualize the production of cytokines in vivo and to characterize how these cytokineproducing populations interact with other cell types.

\section{Double (or More) Labeled Mice}

Interestingly, the difference in fluorescence emission spectra for eGFP and eYFP allows for intravital identification of the two fluorophores in double labeled LysM-eGFP $\times$ Cd11c-eYFP animals (Fenrich et al., 2012). In the context of research on neuroinflammation, these animals are particularly appropriate to study the contribution of resident and peripheral immune cells in neuropathology.

Given the diversity of immune cells that compose the neuroinflammatory response, red fluorescent mice lines were also engineered to generate easy to separate color-coded mice by subsequent breeding. A red knock-in (KI) mouse was created with an RFP sequence (a DsRed variant) replacing the first 279 base pairs of the open reading frame coding for the chemokine receptor type 2 (CCR2). Homozygous CCR2 $2^{\text {RFP/RFP }}$ KI animals were crossed with CX3CR1 $1^{\mathrm{GFP} / \mathrm{GFP}}$ homozygous animals to obtain heterozygous double KI animals CX3CR $1^{+/ \mathrm{GFP}} \mathrm{CCR} 2^{+/ \mathrm{RFP}}$, an elegant "two-colored" mouse model suitable for immunological studies combining red and green fluorophores. In these mice, distinct monocyte populations express the two chemokine receptors. Notably, CX3CR1 distinguished a monocyte subset in peripheral blood, so-called resident and phenotypically recognized as LFA $-1^{+} / \mathrm{LSel}^{-} / \mathrm{Ly} 6 \mathrm{C}^{-} / \mathrm{CCR} 2^{-} / \mathrm{CX} 3 \mathrm{CR} 1^{\text {high }}$, whereas CCR2 marked LFA-1 ${ }^{-} / \mathrm{LSel}^{+} /$ $\mathrm{Ly} 6 \mathrm{C}^{+} / \mathrm{CCR} 2^{+} / \mathrm{CX} 3 \mathrm{CR} 1^{\text {low }}$ inflammatory monocytes (Auffray et al., 2009).

A similar dual reporting strategy might help refine the characterization of immune cells interacting with CX3CR1expressing populations. Indeed, in the B6.Cg- $\operatorname{Tg}(\mathrm{Cx} 3 \mathrm{cl} 1 / \mathrm{mCherry}) 1 \mathrm{Jung} / \mathrm{J}$ mouse line, Exon 1 of the chemokine CX3CL1 (fractalkin), the ligand for CX3CR1, has been replaced with the mCherry fluorescent protein. mCherry is observed in mature neurons in the hippocampus, striatum, cortical layer II, and epithelial cell layers (Kim et al., 2011). When CX3CL1cherry mice are bred with B6.129P-CX3CR1tm1Litt/J mice, the generated double mutant mice allow the study of the CX3CL1 and CX3CR1 interface in tissues and live animals. 
The aforementioned red mice can now be crossed with mice expressing CFP or/and GFP in specific cells to refine the description of the immune interactome. Although there has been limited use of reporter fluorescent mice to investigate the dynamics of infiltrating leukocytes and resident myeloid cells in CNS pathologies to date, some valuable examples are cited below. They illustrate that these mice yield exciting results relative to the behavior of cells expressing the designated fluorophores and to a fine description of cellular population changes in various disease paradigms. This is a fundamental prerequisite in order to provide instructive functional hypotheses for future experiments to test the relevance of cell subsets and to tailor efficient treatments aimed at dampening neuroinflammation by targeting critical cellular responses with candidate drugs.

\section{USE OF TRANSGENIC REPORTER MICE EXAMPLES}

Studies on microglial cell proliferation during early embryonic spinal cord invasion (Rigato et al., 2012), on neuron-glia interactions in the context of neuroinflammation (Garcia et al., 2013), and in neurodegenerative diseases such as Alzheimer's disease (Fuhrmann et al., 2010) or Parkinson's disease (Virgone-Carlotta et al., 2013) have benefited from mouse models involving CX3CR1 and its ligand fractalkin. This pathway was indeed found to play a pivotal role in immunological and inflammatory processes. In a model of experimental autoimmune encephalomyelitis (EAE), CX3CR1-deleted mice exhibited more severe neurologic deficiencies (Utschig et al., 2015). Notably, loss of CX3CR1 was associated with an increased accumulation of $\mathrm{CD} 115^{+} / \mathrm{Ly} 6 \mathrm{C}^{-} / \mathrm{CD} 11 \mathrm{c}^{+}$DCs in EAEaffected brains that correlated with enhanced demyelination and neuronal damage. Despite a lack of in vivo imaging data, overall results suggested that EAE severity observed in CX3CR1-deficient mice was due to an absence of fractalkin signaling on peripheral bone marrow-derived cells.

Our team (Fenrich et al., 2013) crossed the Thy1-CFP-23 (Feng et al., 2000), LysMGFP (Faust et al., 2000), and CD11c-eYFP (Lindquist et al., 2004) mice to create Thy1-CFP/LysM-GFP/CD11c-eYFP triple transgenic mice with multiple fluorescent cell populations (Fig. 4). We studied the spatiotemporal recruitment of resident and peripheral myelomonocytic cells to a spinal cord injury site and their heavily debated role in injury progression. Using chronic, quantitative intravital 2P microscopy of adult mice with spinal cord injuries, we showed that infiltrating LysM-positive and resident CD11c-positive myelomonocytic cells have distinct spatiotemporal recruitment profiles and exhibit changes in morphology, motility, phagocytic activity, and axon interaction patterns over time (Fenrich et al., 2012). Such data underscore the importance of precise timing and targeting of specific cell populations in developing therapies.

Concerning brain tumors (Ricard et al., 2013), we used protocols optimized for orthotopic glioblastoma grafting in mice that were able to recapitulate the biophysical constraints normally governing tumor progression and were suitable for intravital $2 \mathrm{P}$ microscopy. Tumor cells and blood vessels were repeatedly imaged during tumor development. Quantitative correlative analyses of dynamic imaging data over wide fields allowed us to look for correlations between blood vessel density, tumor cell density, and tumor proliferation. Despite extensive vascular remodeling and the formation of new vessels along with tumor growth, no correlation was found between local cell density and the extent of local blood vessel density whatever the tumor area or time points. The technique, moreover, proves useful for comparative analysis of mice subjected to anti-angiogenic treatments that target VEGF or to AMD3100, an antagonist of the CXCR4 receptor. Altogether, these in vivo observations indicate that, in the brain, tumor growth can be sustained without an increase in blood vessel density and point to the role of inflammatory cells to govern tumor growth. In this case establishing and imaging the tumor in LysM-GFP/CD11c-eYFP mice (Ricard et al., 2014) should allow a test of the hypothesis.

\section{FUTURE DIRECTIONS}

Conceivably, the paradigms used in these studies could be adapted to any colored transgenic mouse line to draw general conclusions about the cellular mechanisms contributing to the disease in experimental animal models. Moreover, transgenic mice have emerged as a promising model to study human immunity in vivo (Bonte et al., 2016). The overall goal of combining transgenic reporter mice with $2 \mathrm{P}$ imaging is to confirm that the cell interactions and migrations proposed on the basis of coculture data actually occur in vivo in living and functioning animals.
Mouse Models for Imaging Neuroinflammation 


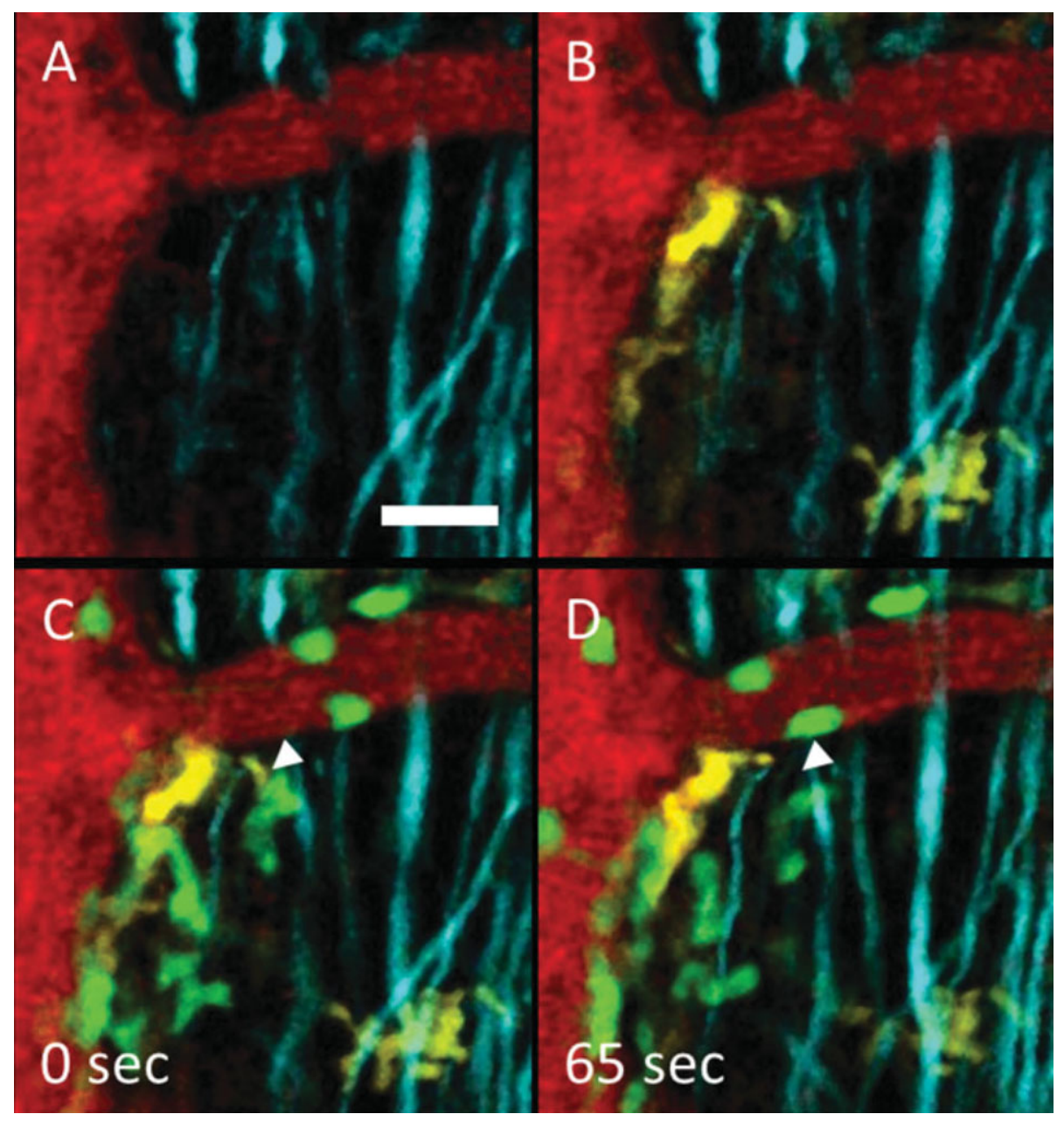

Figure 4 Triple transgenic Thy1-CFP/Cd11c-eYFP/LysM-eGFP fluorescent reporter mouse used to study neuroinflammatory events in vivo by two-photon microscopy. (A) Following injection of 655-Qdot probes, standard two-color imaging highlights blood vessels (red) and Thy1-expressing axons (cyan) in the spinal cord of an adult mouse 17 days after experimental autoimmune encephalomyelitis (EAE) induction. (B) In an additional eYFP channel acquired concomitantly with $A$, the high density of CD11c-eYFP+ microglial cells (yellow) reveals the pathological activation of central nervous system resident immune cells during EAE progression. (C) At this stage of the disease, circulating LysM-eGFP+ peripheral immune cells (green) are also recruited in the parenchyma, as visible in a fourth color channel. (D) Simultaneity of channels acquisition combined with spatial and temporal resolution allows for intravital identification of cellular contact between resident (yellow) and peripheral (green) immune cells (white arrow). These contacts are transient, lasting a few seconds (delay between C and D: $65 \mathrm{sec}$ ). Image acquired at $940 \mathrm{~nm}$ light excitation. Scale bar: $20 \mu \mathrm{m}$.

The combination of multicolor reporter mice with intravital $2 \mathrm{P}$ microscopy is expected to provide valuable and unique information to assess the role of individual genes in the context of the international Knockout Mouse Phenotyping Program (KOMP). By systematically breeding every $\mathrm{KO}$ animal with multicolor fluorescent reporter mice, it will become possible to evaluate the direct and indirect impact of gene deletions on identified cell populations and on the dynamic interactions that they establish with other cellular components.
Moreover, it will be very helpful to cross the reporter mice with available transgenic mouse models of disease. These multiple fluorescence mice would allow for visualizing the evolution of neuroinflammation markers and disease targets throughout the course of the disease in living animals. For example, a transgenic Alzheimer's model was successfully crossed with reporter transgenic mice to image neurons and microglial cells through cranial glass windows (Fuhrmann et al., 2010). This study revealed that microglial cells are 
recruited to the neuron before and not after the elimination of the neuron, with increased migration velocity, and that neuronal elimination depends on intact communication between microglial cells and the neuron via fractalkin and CX3CR1.

Finally, this approach is fully compatible with drug and pharmaceutical tool tests on disease animal models. Even more interesting, the effect of potential drugs would be achieved not only on the disease-targeted cells, but also on neurons, vascularization, and any other desired cell type, with direct correlations between animal health and behavior (Malcor et al., 2012; Ricard and Debarbieux, 2014; Serres et al., 2014; Tang et al., 2015).

The next goals of research will likely be: (1) to distinguish neurotoxic from neuroprotective leukocyte populations; (2) to identify and visualize key molecules and their receptors in vivo; and, (3) to image the targets of future therapeutics together with key outcome predictors such as neuronal integrity.

\section{ACKNOWLEDGMENTS}

The team is supported by Aix-Marseille University, the CNRS, and grants from the National Multiple Sclerosis Society (ARSEP; to G.R.), National Cancer Institute (INCA; to G.R. and F.D.), National French Agency (ANR; to F.D.), Integrated Cancer Research Site (SIRIC), and CIFRE fellowship (to A.J.).

\section{LITERATURE CITED}

Aisen, P.S. 2002. The potential of antiinflammatory drugs for the treatment of Alzheimer's disease. Lancet Neurol. 1:279-284. doi: 10.1016/S1474-4422(02)00133-3.

Aloisi, F., Ria, F., and Adorini, L. 2000. Regulation of T-cell responses by CNS antigenpresenting cells: Different roles for microglia and astrocytes. Immunol. Today 21:141-147. doi: 10.1016/S0167-5699(99)01512-1.

Anandasabapathy, N., Victora, G.D., Meredith, M., Feder, R., Dong, B., Kluger, C., Yao, K., Dustin, M.L., Nussenzweig, M.C., Steinman, R.M, and Liu, K. 2011. Flt3L controls the development of radiosensitive dendritic cells in the meninges and choroid plexus of the steady-state mouse brain. J. Exp. Med. 208:1695-1705. doi: 10.1084/jem.20102657.

Auffray, C., Sieweke, M.H., and Geissmann, F. 2009. Blood monocytes: Development, heterogeneity, and relationship with dendritic cells. Annu. Rev. Immunol. 27:669-692. doi: 10.1146/annurev.immunol.021908.132557.

Banati, R.B., Gehrmann, J., Schubert, P., and Kreutzberg, G.W. 1993. Cytotoxicity of microglia. Glia 7:111-118. doi: 10.1002/glia.440070117.
Battistini, L., Fischer, F.R., Raine, C.S., and Brosnan, C.F. 1996. CD1b is expressed in multiple sclerosis lesions. J. Neuroimmunol. 67:145-151. doi: 10.1016/0165-5728(96)00045-8.

Block, M.L. and Hong, J.-S. 2005. Microglia and inflammation-mediated neurodegeneration: Multiple triggers with a common mechanism. Prog. Neurobiol. 76:77-98. doi: 10.1016/j.pneurobio.2005.06.004.

Boes, M., Cerny, J., Massol, R., Op den Brouw, M., Kirchhausen, T., Chen, J., and Ploegh, H. 2002. T-cell engagement of dendritic cells rapidly rearranges MHC class II transport. $\mathrm{Na}$ ture 418:983-988. doi: 10.1038/nature01004.

Bonte, S., Snauwaert, S., Vanhee, S., Dolens, A.C., Taghon, T., Vandekerckhove, B., and Kerre, T. 2016. Humanized mice to study human T cell development. Methods Mol. Biol. 1323:253272. doi: 10.1007/978-1-4939-2809-5_21.

Bulloch, K., Miller, M.M., Gal-Toth, J., Milner, T.A., Gottfried-Blackmore, A., Waters, E.M., Kaunzner, U.W., Liu, K., Lindquist, R., Nussenzweig, M.C., Steinman R.M., and McEwen, B.S. 2008. CD11c/EYFP transgene illuminates a discrete network of dendritic cells within the embryonic, neonatal, adult, and injured mouse brain. J. Comp. Neurol. 508:687-710. doi: 10.1002/cne.21668.

Chen, M.-K. and Guilarte, T.R. 2008. Translocator protein $18 \mathrm{kDa}$ (TSPO): Molecular sensor of brain injury and repair. Pharmacol. Ther. 118:117. doi: 10.1016/j.pharmthera.2007.12.004.

Chen, X., Kezic, J., Bernard, C., and McMenamin, P.G. 2013. Rd8 mutation in the Crb1 gene of CD11c-eYFP transgenic reporter mice results in abnormal numbers of CD11c-positive cells in the retina. J. Neuropathol. Exp. Neurol. 72:782790. doi: 10.1097/NEN.0b013e31829e8375.

Das, A., Chai, J.C., Kim, S.H., Park, K.S., Lee, Y.S., Jung, K.H., and Chai, Y.G. 2015. Dual RNA sequencing reveals the expression of unique transcriptomic signatures in lipopolysaccharide-induced BV-2 microglial cells. PloS One 10:e121117. doi: 10.1371/journal.pone.0121117.

Dorand, R.D., Barkauskas, D.S., Evans, T.A., Petrosiute, A., and Huang, A.Y. 2014. Comparison of intravital thinned skull and cranial window approaches to study CNS immunobiology in the mouse cortex. Intravital 3:e29728. doi: 10.4161/intv.29728.

Duffield, J.S., Forbes, S.J., Constandinou, C.M., Clay, S., Partolina, M., Vuthoori, S., Wu, S., Lang, R., and Iredale, J.P. 2005. Selective depletion of macrophages reveals distinct, opposing roles during liver injury and repair. J. Clin. Invest. 115:56-65. doi: 10.1172/JCI200522675.

Faust, N., Varas, F., Kelly, L.M., Heck, S., and Graf, T. 2000. Insertion of enhanced green fluorescent protein into the lysozyme gene creates mice with green fluorescent granulocytes and macrophages. Blood 96:719-726.

Feng, G., Mellor, R.H., Bernstein, M., Keller-Peck, C., Nguyen, Q.T., Wallace, M., Nerbonne, J.M., Lichtman, J.W., and Sanes, J.R. 2000. Imaging
Mouse Models for Imaging Neuroinflammation 
neuronal subsets in transgenic mice expressing multiple spectral variants of GFP. Neuron 28:4151. doi: 10.1016/S0896-6273(00)00084-2.

Fenrich, K.K., Weber, P., Rougon, G., and Debarbieux, F. 2013. Implanting glass spinal cord windows in adult mice with experimental autoimmune encephalomyelitis. J. Vis. Exp. (82):e50826. doi: 10.3791/50826.

Fenrich, K.K., Weber, P., Hocine, M., Zalc, M., Rougon, G., and Debarbieux, F. 2012. Longterm in vivo imaging of normal and pathological mouse spinal cord with subcellular resolution using implanted glass windows. $J$. Physiol. 590:3665-3675. doi: 10.1113/jphysiol.2012.230532.

Fuhrmann, M., Bittner, T., Jung, C.K.E., Burgold, S., Page, R.M., Mitteregger, G., Haass, C., LaFerla, F.M., Kretzschmar, H., and Herms, J. 2010. Microglial Cx3cr1 knockout prevents neuron loss in a mouse model of Alzheimer's disease. Nat. Neurosci. 13:411-413. doi: $10.1038 / \mathrm{nn} .2511$.

Gao, H.-M., Liu, B., Zhang, W., and Hong, J.S. 2003. Critical role of microglial NADPH oxidase-derived free radicals in the in vitro MPTP model of Parkinson's disease. FASEB $J$. 17:1954-1956. doi: 10.1096/fj.03-0109fje

Garcia, J.A., Cardona, S.M., and Cardona, A.E. 2013. Analyses of microglia effector function using CX3CR1-GFP knock-in mice. Methods Mol. Biol. 1041:307-317. doi: 10.1007/978-1-62703-520-0_27.

Gimsa, U., Mitchison, N.A., and BrunnerWeinzierl, M.C. 2013. Immune privilege as an intrinsic CNS property: Astrocytes protect the CNS against T-cell-mediated neuroinflammation. Mediators Inflamm. 2013:1-11. doi: $10.1155 / 2013 / 320519$

Ginhoux, F., Greter, M., Leboeuf, M., Nandi, S., See, P., Gokhan, S., Mehler, M.F, Conway, S.J., Ng, L.G., Stanley, E.R., Samokhvalov, I.M., and Merad, M. 2010. Fate mapping analysis reveals that adult microglia derive from primitive macrophages. Science 330:841-845. doi: 10.1126/science.1194637.

Gong, Y. 2015. The evolving capabilities of rhodopsin-based genetically encoded voltage indicators. Curr. Opin. Chem. Biol. 27:84-89. doi: 10.1016/j.cbpa.2015.05.006.

Greter, M., Lelios, I., and Croxford, A.L. 2015. Microglia versus myeloid cell nomenclature during brain inflammation. Front. Immunol. 6:249. doi: 10.3389/fimmu.2015.00249.

Güç, E., Fankhauser, M., Lund, A.W., Swartz, M.A., and Kilarski, W.W. 2014. Long-term intravital immunofluorescence imaging of tissue matrix components with epifluorescence and two-photon microscopy. J. Vis. Exp. (86):e51388. doi: 10.3791/51388.

Hailer, N.P., Heppner, F.L., Haas, D., and Nitsch, R. 1998. Astrocytic factors deactivate antigen presenting cells that invade the central nervous system. Brain Pathol. 8:459-474. doi: 10.1111/j.1750-3639.1998.tb00168.x.
Hindinger, C., Bergmann, C.C., Hinton, D.R., Phares, T.W., Parra, G.I., Hussain, S., Savarin, C., Atkinson, R.D., and Stohlman, S.A. 2012. IFN- $\gamma$ signaling to astrocytes protects from autoimmune mediated neurological disability. PloS One 7:e42088. doi: 10.1371/journal.pone.0042088.

Hoover, E.E. and Squier, J.A. 2013. Advances in multiphoton microscopy technology. Nat. Photonics 7:93-101. doi: 10.1038/nphoton.2012.361.

Iqbal, A.J., McNeill, E., Kapellos, T.S., ReganKomito, D., Norman, S., Burd, S., Smart, N., Machemer, D.E.W., Stylianou, E., McShane, H., Channon, K.M., Chawla, A., and Greaves, D.R. 2014. Human CD68 promoter GFP transgenic mice allow analysis of monocyte to macrophage differentiation in vivo. Blood 124:e33-e44. doi: 10.1182/blood-2014-04-568691.

Jacobs, A.H. and Tavitian, B. 2012. Noninvasive molecular imaging of neuroinflammation. $J$. Cereb. Blood Flow Metab. 32:1393-1415. doi: 10.1038/jcbfm.2012.53.

Jiang, R., Haustein, M.D., Sofroniew, M.V, and Khakh, B.S. 2014. Imaging intracellular $\mathrm{Ca}^{2+}$ signals in striatal astrocytes from adult mice using genetically-encoded calcium indicators. $J$. Vis. Exp. (93):e51972. doi: 10.3791/51972.

Jung, S., Aliberti, J., Graemmel, P., Sunshine, M.J., Kreutzberg, G.W., Sher, A., and Littman, D.R. 2000. Analysis of fractalkine receptor CX(3)CR1 function by targeted deletion and green fluorescent protein reporter gene insertion. Mol. Cell Biol. 20:4106-4114. doi: 10.1128/ MCB.20.11.4106-4114.2000.

Jung, S., Unutmaz, D., Wong, P., Sano, G.-I., De los Santos, K., Sparwasser, T., Wu, S., Vuthoori, S., Ko, K., Zavala, F., Pamer, E.G., Littman, D.R., and Lang, R.A. 2002. In vivo depletion of CD11c+ dendritic cells abrogates priming of CD8+ $\mathrm{T}$ cells by exogenous cellassociated antigens. Immunity 17:211-220. doi: 10.1016/S1074-7613(02)00365-5.

Kannan, S., Balakrishnan, B., Muzik, O., Romero, R., and Chugani, D. 2009. Positron emission tomography imaging of neuroinflammation. J. Child Neurol. 24:1190-1199. doi: 10.1177/0883073809338063.

Kawakami, N. and Flügel, A. 2010. Knocking at the brain's door: Intravital two-photon imaging of autoreactive T cell interactions with CNS structures. Semin. Immunopathol. 32:275-287. doi: 10.1007/s00281-010-0216-x.

Kierdorf, K., Erny, D., Goldmann, T., Sander, V., Schulz, C., Perdiguero, E.G., Wieghofer, P., Heinrich, A., Riemke, P., Hölscher, C., Müller, D.N., Luckow, B., Brocker, T., Debowski, K., Fritz, G., Opdenakker, G., Diefenbach, A., Biber, K., Heikenwalder, M., Geissmann, F., Rosenbauer, F., and Prinz, M. 2013. Microglia emerge from erythromyeloid precursors via Pu.1- and Irf8-dependent pathways. Nat. Neurosci. 16:273-280. doi: 10.1038/nn.3318.

Kim, K.-W., Vallon-Eberhard, A., Zigmond, E., Farache, J., Shezen, E., Shakhar, G., Ludwig, 
A., Lira, S.A., and Jung, S. 2011. In vivo structure/function and expression analysis of the CX3C chemokine fractalkine. Blood 118:e156e167. doi: 10.1182/blood-2011-04-348946.

Kore, R.A. and Abraham, E.C. 2014. Inflammatory cytokines, interleukin-1 beta and tumor necrosis factor-alpha, upregulated in glioblastoma multiforme, raise the levels of CRYAB in exosomes secreted by U373 glioma cells. Biochem. Biophys. Res. Commun. 453:326-331. doi: 10.1016/j.bbrc.2014.09.068.

Koyanagi, M., Kawakabe, S., and Arimura, Y. 2015. A comparative study of colorimetric cell proliferation assays in immune cells. Cytotechnology. [ePub ahead of print]. doi: 10.1007/s10616-015-9909-2.

Kwan, A.C., Duff, K., Gouras, G.K., and Webb, W.W. 2009. Optical visualization of Alzheimer's pathology via multiphoton-excited intrinsic fluorescence and second harmonic generation. Opt. Express 17:3679-3689. doi: 10.1364/OE.17.003679.

Laffray, S., Pagès, S., Dufour, H., De Koninck, P., De Koninck, Y., and Côté, D. 2011. Adaptive movement compensation for in vivo imaging of fast cellular dynamics within a moving tissue. PloS One 6:e19928. doi: 10.1371/journal.pone.0019928.

Lindquist, R.L., Shakhar, G., Dudziak, D., Wardemann, H., Eisenreich, T., Dustin, M.L., and Nussenzweig, M.C. 2004. Visualizing dendritic cell networks in vivo. Nat. Immunol. 5:12431250. doi: 10.1038/ni1139.

Littman, D.R. 2013. An inducible cre recombinase driven by $\mathrm{Cx} 3 \mathrm{cr} 1$. MGI Direct Data Submission, available at http://www. informatics.jax.org/allele/MGI:5450813.

London, A., Cohen, M., and Schwartz, M. 2013. Microglia and monocyte-derived macrophages: Functionally distinct populations that act in concert in CNS plasticity and repair. Front. Cell Neurosci. 7:34. doi: 10.3389/fncel.2013.00034.

Mahou, P., Zimmerley, M., Loulier, K., Matho, K.S., Labroille, G., Morin, X., Supatto, W., Livet, J., Débarre, D., and Beaurepaire, E. 2012. Multicolor two-photon tissue imaging by wavelength mixing. Nat. Methods 9:815-818. doi: 10.1038/nmeth.2098.

Malcor, J.-D., Payrot, N., David, M., Faucon, A., Abouzid, K., Jacquot, G., Floquet, N., Debarbieux, F., Rougon, G., Martinez, J., Khrestchatisky, M., Vlieghe, P., and Lisowski, V. 2012. Chemical optimization of new ligands of the low-density lipoprotein receptor as potential vectors for central nervous system targeting. J. Med. Chem. 55:2227-2241. doi: $10.1021 / \mathrm{jm} 2014919$.

Marker, D.F., Tremblay, M.-E., Lu, S.-M., Majewska, A.K., and Gelbard, H.A. 2010. A thin-skull window technique for chronic two-photon in vivo imaging of murine microglia in models of neuroinflammation. J. Vis. Exp. (43):e2059. doi: $10.3791 / 2059$.

Marvin, J.S., Borghuis, B.G., Tian, L., Cichon, J., Harnett, M.T., Akerboom, J., Gordus, A.,
Renninger, S.L., Chen, T.-W., Bargmann, C.I., Orger, M.B., Schreiter, E.R., Demb, J.B., Gan, W.-B., Hires, S.A., and Looger, L.L. 2013. An optimized fluorescent probe for visualizing glutamate neurotransmission. Nat. Methods 10:162-170. doi: 10.1038/nmeth.2333.

McAllister, A.K. and van de Water, J. 2009. Breaking boundaries in neuralimmune interactions. Neuron 64:9-12. doi: 10.1016/j.neuron.2009.09.038.

Naidenko, O.V, Koezuka, Y., and Kronenberg, M. 2000. CD1-mediated antigen presentation of glycosphingolipids. Microbes Infect. 2:621-631. doi: 10.1016/S1286-4579(00)00363-4.

Niesner, R., Andresen, V., and Gunzer, M. 2008. Intravital two-photon microscopy: Focus on speed and time resolved imaging modalities. Immunol. Rev. 221:7-25. doi: 10.1111/j.1600-065X.2008.00582.x.

Parkhurst, C.N., Yang, G., Ninan, I., Savas, J.N., Yates, J.R., 3rd, Lafaille, J.J., Hempstead, B.L., Littman, D.R., and Gan, W.B. 2013. Microglia promote learning-dependent synapse formation through brain-derived neurotrophic factor. Cell 155:1596-1609. doi: 10.1016/j.cell.2013.11.030..

Pasternak, O., Kubicki, M., and Shenton, M.E. 2015. In vivo imaging of neuroinflammation in schizophrenia. Schizophr. Res. [ePub ahead of print]. doi:10.1016/j.schres.2015.05.034.

Perdiguero, E.G., Klapproth, K., Schulz, C., Busch, K., Azzoni, E., Crozet, L., Garner, H., Trouillet, C., de Bruijn, M.F., Geissmann, F., and Rodewald, H. 2014. Tissue-resident macrophages originate from yolk-sac-derived erythro-myeloid progenitors. Nature 518:547551. doi: 10.1038/nature13989.

Prendergast, F.G. and Mann, K.G. 1978. Chemical and physical properties of aequorin and the green fluorescent protein isolated from Aequorea forskålea. Biochemistry 17:3448-3453. doi: 10.1021/bi00610a004.

Ricard, C. and Debarbieux, F.C. 2014. Six-color intravital two-photon imaging of brain tumors and their dynamic microenvironment. Front. Cell Neurosci. 8:57. doi: 10.3389/fncel.2014.00057.

Ricard, C., Stanchi, F., Rougon, G., and Debarbieux, F. 2014. An orthotopic glioblastoma mouse model maintaining brain parenchymal physical constraints and suitable for intravital twophoton microscopy. J. Vis. Exp. (86):e51108. doi: $10.3791 / 51108$.

Ricard, C., Stanchi, F., Rodriguez, T., Amoureux, M.-C., Rougon, G., and Debarbieux, F. 2013. Dynamic quantitative intravital imaging of glioblastoma progression reveals a lack of correlation between tumor growth and blood vessel density. PloS One 8:e72655. doi: 10.1371/journal.pone.0072655.

Rigato, C., Swinnen, N., Buckinx, R., Couillin, I., Mangin, J.-M., Rigo, J.-M., Legendre, P., and Le Corronc, H. 2012. Microglia proliferation is controlled by $\mathrm{P} 2 \mathrm{X} 7$ receptors in a Pannexin-1-independent manner during early embryonic spinal cord invasion.
Mouse Models for Imaging Neuroinflammation 
J. Neurosci. 32:11559-11573. doi: 10.1523/ JNEUROSCI.1042-12.2012.

Rock, R.B. and Peterson, P.K. 2006. Microglia as a pharmacological target in infectious and inflammatory diseases of the brain. J. Neuroimmune Pharmacol. 1:117-126. doi: 10.1007/s11481-006-9012-8.

Rohde, G.K., Dawant, B.M., and Lin, S.-F. 2005. Correction of motion artifact in cardiac optical mapping using image registration. IEEE Trans. Biomed. Eng. 52:338-341. doi: 10.1109/TBME.2004.840464.

Rupprecht, R., Papadopoulos, V., Rammes, G., Baghai, T. C., Fan, J., Akula, N., Groyer, G., Adams, D., and Schumacher, M. 2010. Translocator protein $(18 \mathrm{kDa})$ (TSPO) as a therapeutic target for neurological and psychiatric disorders. Nat. Rev. Drug Discov. 9:971-988. doi: $10.1038 /$ nrd3295.

Saba, W., Goutal, S., Kuhnast, B., Dollé, F., Auvity, S., Fontyn, Y., Cayla, J., Peyronneau, M.-A., Valette, H., and Tournier, N. 2015. Differential influence of propofol and isoflurane anesthesia in a non-human primate on the brain kinetics and binding of [(18) F]DPA-714, a positron emission tomography imaging marker of glial activation. Eur. J. Neurosci. 42:1738-1745. doi: 10.1111/ejn.12946.

Schwartz, M. 2003. Macrophages and microglia in central nervous system injury: Are they helpful or harmful? J. Cereb. Blood Flow Metab. 23:385-394. doi: 10.1097/01.WCB.0000061881.75234.5E.

Serres, E., Debarbieux, F., Stanchi, F., Maggiorella, L., Grall, D., Turchi, L., Burel-Vandenbos, F., Figarella-Branger, D., Virolle, T., Rougon, G., and Van Obberghen-Schilling, E. 2014. Fibronectin expression in glioblastomas promotes cell cohesion, collective invasion of basement membrane in vitro and orthotopic tumor growth in mice. Oncogene 33:3451-3462. doi: 10.1038/onc.2013.305.

Shechter, R., Miller, O., Yovel, G., Rosenzweig, N., London, A., Ruckh, J., Kim, K.W., Klein, E., Kalchenko, V., Bendel, P., Lira, S.A., Jung, S., and Schwartz, M. 2013. Recruitment of beneficial M2 macrophages to injured spinal cord is orchestrated by remote brain choroid plexus. Immunity 38:555-569. doi: 10.1016/j.immuni.2013.02.012.

Singh, Y., Dyson, J., and Garden, O.A. 2011. Use of SNARF-1 to measure murine T cell proliferation in vitro and its application in a novel regulatory T cell suppression assay. Immunol. Lett. 140:2129. doi: 10.1016/j.imlet.2011.05.011.

Stepanenko, O.V., Stepanenko, O.V., Shcherbakova, D.M., Kuznetsova, I.M., Turoverov, K.K., and Verkhusha, V.V. 2011. Modern fluorescent proteins: From chromophore formation to novel intracellular applications. BioTechniques 51:313-327. doi: 10.2144/000113765.

Mouse Models for Imaging Neuroinflammation

Tang, P., Hu, G., Gao, Y., Li, W., Yao, S., Liu, Z., and Ma, D. 2014. The microwave adsorption behavior and microwave-assisted heteroatoms doping of graphene-based nano-carbon materials. Sci. Rep. 4:5901. doi:10.1038/srep05901.

Tang, P., Zhang, Y., Chen, C., Ji, X., Ju, F., Liu, X., Gan, W.-B., He, Z., Zhang, S., Li, W., and Zhang, L. 2015. In vivo two-photon imaging of axonal dieback, blood flow, and calcium influx with methylprednisolone therapy after spinal cord injury. Sci. Rep. 5:9691. doi: 10.1038/ srep09691.

Tauskela, J.S., Hewitt, K., Kang, L.P., Comas, T., Gendron, T., Hakim, A., Hogan, M., Durkin, J., and Morley, P. 2000. Evaluation of glutathione-sensitive fluorescent dyes in cortical culture. Glia 30:329-341. doi: 10.1002/(SICI)1098-1136(200006)30:4\%3c329 ::AID-GLIA20\%3e3.0.CO;2-R.

Taylor, J.M., Saunter, C.D., Love, G.D., Girkin, J.M., Henderson, D.J., and Chaudhry, B. 2011. Real-time optical gating for threedimensional beating heart imaging. J. Biomed. Opt. 16:116021. doi: 10.1117/1.3652892.

Tóth, M., Doorduin, J., Häggkvist, J., Varrone, A., Amini, N., Halldin, C., and Gulyás, B. 2015. Positron emission tomography studies with [11C]PBR28 in the healthy rodent brain: Validating SUV as an outcome measure of neuroinflammation. PLoS One 10:e0125917. doi: 10.1371/journal.pone.0125917.

Tsai, C.-K., Chen, Y.-S., Wu, P.-C., Hsieh, T.Y., Liu, H.-W., Yeh, C.-Y., Lin, W.-L., Chia, J.-S., and Liu, T.-M. 2012. Imaging granularity of leukocytes with third harmonic generation microscopy. Biomed. Opt. Express 3:2234-2243. doi: 10.1364/BOE.3.002234.

Utschig, L., Soltau, S., and Tiede, D. 2015. Lightdriven hydrogen production from photosystem I-catalyst hybrids. Curr. Opin. Chem. Biol. 25:18. doi: 10.1016/j.cbpa.2014.11.019.

Vandepitte, J., Maes, J., Van Cleynenbreugel, B., Van Poppel, H., Lerut, E., Agostinis, P., and de Witte, P.A.M. 2010. An improved orthotopic rat bladder tumor model using Dil-loaded fluorescent AY-27 cells. Cancer Biol. Ther. 9:986-993. doi: 10.4161/cbt.9.12.11638.

Venneti, S., Lopresti, B., and Wiley, C. 2013. Molecular imaging of microglia/macrophages in the brain. Glia 61:10-23. doi: 10.1002/glia.22357.

Virgone-Carlotta, A., Uhlrich, J., Akram, M.N., Ressnikoff, D., Chrétien, F., Domenget, C., Gherardi, R., Despars, G., Jurdic, P., Honnorat, J., Nataf, S., and Touret, M. 2013. Mapping and kinetics of microglia/neuron cell-tocell contacts in the 6-OHDA murine model of Parkinson's disease. Glia 61:1645-1658. doi: 10.1002/glia.22546.

Weiner, H.L. and Selkoe, D.J. 2002. Inflammation and therapeutic vaccination in CNS diseases. Nature 420:879-884. doi: 10.1038/nature01325.

Winkler, M., Jester, B., Nien-Shy, C., Massei, S., Minckler, D.S., Jester, J.V, and Brown, D.J. 2010. High resolution three-dimensional reconstruction of the collagenous matrix of the human optic nerve head. Brain Res. Bull. 81:339-348. doi: 10.1016/j.brainresbull.2009.06.001. 
Yan, H., He, L., Zhao, W., Li, J., Xiao, Y., Yang, R., and Tan, W. 2014. Poly $\beta$-cyclodextrin/TPdye nanomicelle-based two-photon nanoprobe for caspase- 3 activation imaging in live cells and tissues. Anal. Chem. 86:11440-11450. doi: 10.1021/ac503546r.

Yang, M., Wei, X., Li, J., Heine, L.A., Rosenwasser, R., and Iacovitti, L. 2010. Changes in host blood factors and brain glia accompanying the functional recovery after systemic administration of bone marrow stem cells in ischemic stroke rats. Cell Transplant. 19:1073-1084. doi: 10.3727/096368910X503415.

Zlokovic, B. 2008. The blood-brain barrier in health and chronic neurodegenerative disorders. Neuron 57:178-201. doi: 10.1016/j.neuron.2008.01.003.

Mouse Models for Imaging Neuro- 